\title{
BMJ Open Experiences with traumatic events, consequences and care among people with visual impairment and post- traumatic stress disorder: a qualitative study from The Netherlands
}

\author{
Alida J van der Ham (D) , ${ }^{1,2}$ Hilde P A van der Aa, ${ }^{1,2}$ Peter Verstraten, ${ }^{2}$ \\ Ger H M B van Rens, ${ }^{1,3}$ Ruth M A van Nispen ${ }^{1}$
}

To cite: van der Ham AJ, van der Aa HPA, Verstraten P, et al. Experiences with traumatic events, consequences and care among people with visual impairment and posttraumatic stress disorder: a qualitative study from The Netherlands. BMJ Open 2021;11:e041469. doi:10.1136/ bmjopen-2020-041469

- Prepublication history and additional material for this paper is available online. To view these files, please visit the journal online (http://dx.doi.org/10. 1136/bmjopen-2020-041469)

Received 11 June 2020 Revised 18 December 2020 Accepted 28 December 2020

Check for updates

(c) Author(s) (or their employer(s)) 2021. Re-use permitted under CC BY-NC. No commercial re-use. See rights and permissions. Published by BMJ.

${ }^{1}$ Ophthalmology, Amsterdam UMC Locatie VUmc, Amsterdam, The Netherlands

${ }^{2}$ Expertise Innovation Knowledge, Robert Coppes Foundation, Vught, The Netherlands

${ }^{3}$ Ophthalmology, Elkerliek Hospital, Helmond, The Netherlands

Correspondence to Dr Alida J van der Ham; a.j.vander.ham@vu.nl

\section{ABSTRACT}

Objective Having a visual impairment is known to be associated with an increased vulnerability to (potentially) traumatic events. Little is known about how people with visual impairment experience and process such events. This qualitative study aimed to provide more insight into experiences with traumatic events, consequences of traumatic events and post-traumatic stress disorder (PTSD)-related care among people with visual impairment and PTSD.

Methods Eighteen persons with visual impairment and (a history of) PTSD were interviewed. Among them were 14 women and 4 men aged between 23 and 66 years. Recruitment of participants was done through health professionals from two low-vision service centres and a patient association for people with eye diseases and visual impairment in The Netherlands. Interviews focused on experiences with (1) traumatic events, (2) consequences of traumatic events and (3) PTSD-related care. Thematic content analysis of interview data was performed using ATLAS.ti. The COnsolidated criteria for REporting Qualitative research (COREQ) checklist was used to check for completeness and transparency of the study. Data were collected between 2018 and 2020.

Results The most commonly reported traumatic events were sexual and physical abuse. Many participants experienced that their impairment had negatively affected their acceptance by others, independence and self-esteem, increasing their vulnerability for traumatic events. Additionally, having a visual impairment negatively impacted participants' ability to respond to situations and aggravated post-traumatic stress reactions. Existing treatments seem suitable for people with visual impairment when accommodated to the impairment.

Conclusions Having a visual impairment may affect traumatic events and post-traumatic stress reactions, particularly by contributing to low self-esteem, problems in social interactions and a lack of visual information. Insights from this study provide starting points for adapting pretraumatic and post-traumatic care to the needs of people with visual impairment.

\section{Strengths and limitations of this study}

- This exploratory, qualitative study provides in-depth insights into a sensitive and largely unexplored topic: the combination of post-traumatic stress and visual impairment.

- Participants were recruited through two low-vision service centres and a patient association, resulting in a diverse study population with respect to age, visual impairment and living conditions, which contributed to the richness of data.

- Two patient representatives were involved in the research process, which specifically aided in increasing feasibility and reducing the burden of data collection for participants.

- The study provides limited insight into experiences of persons with visual impairment and single trauma not involving abuse and does not allow for comparisons with the general population.

- The retrospective nature of the interviews may have resulted in recall bias.

\section{INTRODUCTION}

Having a visual impairment is known to be associated with an increased vulnerability to experiencing events such as falls, traffic accidents and abuse. ${ }^{12}$ Such events can be highly stressful and threatening and may trigger the development of a post-traumatic stress disorder (PTSD). PTSD is a mental disorder that may develop after exposure to traumatic events. ${ }^{3}$ Based on the Diagnostic and Statistical Manual of MentalDisorders, Fifth Edition (DSM5), to qualify for a PTSD diagnosis, a person must display one or more symptoms from each of the following four clusters: re-experiencing the event, avoidance of reminders of trauma, negative thoughts and emotions, and changes in arousal and reactivity. ${ }^{4}$ In addition, these symptoms must persist for at least 1 month after the event and cause significant 
problems in functioning on important life domains (eg, social and vocational). According to diagnostic criteria for PTSD, vision loss in itself is not considered a traumatic event, unless it involves threatened death, serious injury or sexual violence. PTSD in people with visual impairment is therefore more likely to result from traumatic events which are not or only indirectly related to their impairment.

A limited number of studies investigated traumatic event exposure and PTSD prevalence among people with visual impairment. The available literature suggests that traumatic experiences and PTSD are common within this group. Heir et al $\tilde{l}^{5}$ found that $80 \%$ of the people with visual impairment in their study had experienced at least one traumatic event, and 12\% had PTSD. A recent literature review describes PTSD prevalence rates ranging from $4 \%$ to $50 \%$ in this population. ${ }^{6}$ These percentages seem high compared with findings from a large epidemiological study by the World Mental Health Surveys Consortium, reporting a lifetime prevalence of PTSD of 3.9\%. ${ }^{7}$ However, due to a lack of a comparative research, it remains unclear whether these numbers are significantly higher among non-sighted populations compared with sighted populations. Nevertheless, the current evidence indicates that PTSD seems a relevant public health problem among people with visual impairment, which requires further investigation.

As visual impairment appears to be associated with unique experiences and coping styles with respect to trauma, ${ }^{26}$ clients may also experience specific challenges when receiving PTSD-related care. Visual impairment may interact with the access and quality of social support and with the likelihood of getting assistance or treatment in the mental healthcare system. ${ }^{8}$ To the best of our knowledge, experiences and specific needs regarding care for people with visual impairment and PTSD have not been studied yet. Therefore, this qualitative study aimed for an in-depth exploration of experiences with traumatic events, consequences of traumatic events and PTSD-related care among people with visual impairment and PTSD.

\section{METHODS}

\section{Study design}

This study was based in The Netherlands and carried out between 2018 and 2020. The study used an explorative, qualitative design, including in-depth interviews with people with visual impairment and (a history of) PTSD. The COnsolidated criteria for REporting Qualitative research (COREQ) checklist was used to check for completeness and transparency of the study.

\section{Study population}

The population included adults (18 years and older) with visual impairment and (a history of) PTSD. Visual impairment includes both low vision and blindness. ${ }^{9}$ Low vision is defined as visual acuity of less than $6 / 18$, but equal to or better than $3 / 60$, or a corresponding visual field loss to less than $20^{\circ}$ in the better eye with best possible correction. Blindness is defined as visual acuity of less than $3 / 60$, or a corresponding visual field loss to less than $10^{\circ}$ in the better eye with best possible correction. PTSD was defined by a patient-reported past or present diagnosis of PTSD by a health professional. Additional inclusion criteria were undergoing PTSD-related treatment not longer than 5 years ago, being able to understand and respond to questions, and being psychologically stable enough to discuss trauma-related topics.

Recruitment of participants was done through two channels: health professionals of two low-vision service centres and a patient association for people with eye diseases and visual impairment (The Eye Association Netherlands). Health professionals of low-vision service centres purposively recruited participants who met the inclusion criteria. Selection through the patient association involved a convenience sample of members who responded to a call in the association's newsletter. Inclusion criteria were specified in the call and doublechecked during a brief intake by telephone with potential participants. All potential participants received a patient information letter and the informed consent form. After participants consented to participate, an interview was scheduled at the time and place of their preference. In total, 18 participants were included in the study.

\section{Interviews}

In-depth interviews were carried out by the first author (LH) to explore participants' experiences with trauma, PTSD and PTSD-related care. An interview guide consisting of open and closed questions was used to structure the interviews in six parts: (1) an introduction by the interviewer, explaining aims and procedures; (2) general questions about the participants, inquiring about their social network, education, work and visual impairment; (3) experiences with traumatic events; (4) consequences of traumatic events according to DSM- 5 criteria for PTSD; (5) experiences with PTSD-related care; and (6) concluding questions, summarising and verifying information obtained. Throughout the interview, special attention was given to the role of visual impairment. The interview guide can be found in the online supplemental materials.

At the end of the interview, interviewees received a gift certificate for their participation. Interviews lasted between 55 and $150 \mathrm{~min}$. No repeated interviews were carried out. All interviews were audio-recorded and transcribed verbatim. A summary was made of each interview and sent to the interviewee for a member check. Participants were able to inspect the interview summary with the help of a screen reading software or an enlarged font size, or by asking a family member or trusted care provider to read it out loud to them. Member checking led to several additions and adjustments by participants. 
Table 1 Overview of themes, subthemes and relative importance

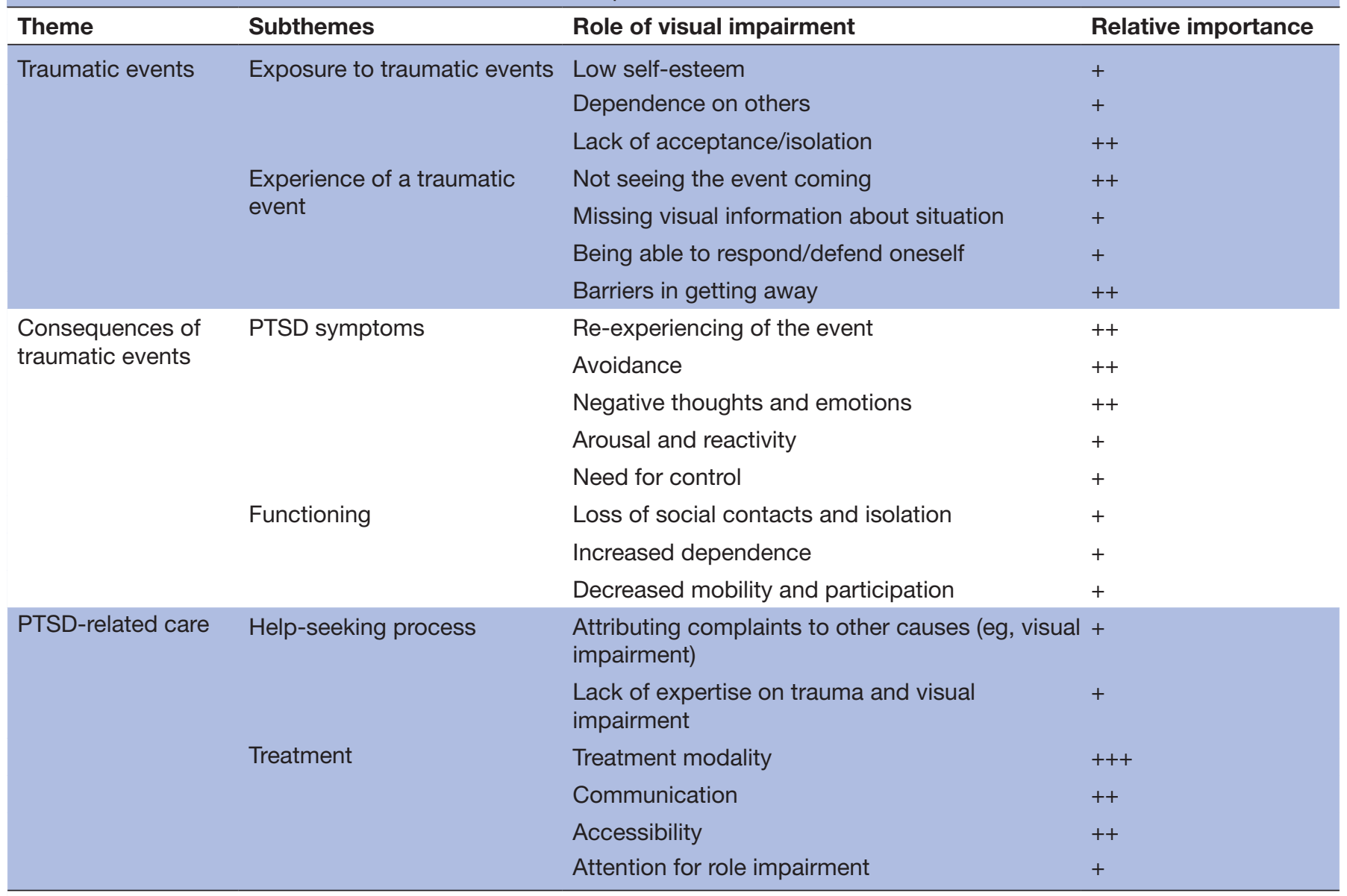

*Indication of relative importance of sub-themes with + (=mentioned in several interviews), ++ (mentioned in approximately half of the interviews) and +++ (=mentioned in a majority of the interviews)

PTSD, post-traumatic stress disorder.

\section{Analysis}

Thematic analysis of the interview data took place in three steps following an iterative process of data collection and analysis. ${ }^{10}$ The first step involved open coding by thoroughly reading transcripts and assigning provisional codes. Second, open codes were reviewed and clustered into main themes and subthemes. The main themes were based on the topics included in the interview guide: (1) experiences with traumatic events, (2) consequences of traumatic events and (3) PTSD-related care. Subcategories were identified based on the provisional codes from the open coding process. Open coding and establishment of main themes and subthemes were done by two people to guarantee inter-rater reliability. The final step involved reviewing of all transcripts based on the main themes, subthemes and specification of the various roles of visual impairment for each subtheme (table 1). ATLAS.ti8 was used to facilitate the analysis process.

\section{Ethical considerations}

During the entire research, specific attention was paid to respect key principles of care ethics as described by Barnes and Cotterel. ${ }^{11}$ Special attention was paid to accessibility with respect to visual impairment by offering information and forms in the format preferred by participants and by arranging interviews at locations that were easily accessible (ie, the participants' home, a care institution or local meeting centre). In addition, preventive measures were taken with regard to the potentially sensitive nature of questions by actively inquiring whether participants felt comfortable, whether there were topics they did not want to elaborate on and emphasising that they could take a break or stop at any time. Interviewees could bring a relative or another trusted person to the interview if they preferred, which occurred in three cases.

\section{Patient and public involvement}

Two patient representatives were consulted during three meetings about the research design, data collection procedures and interpretation of preliminary findings. They were specifically asked to reflect on feasibility and burden of the data collection for the target population. One of the patient representatives also assisted in the recruitment of participants through a patient organisation. 


\begin{tabular}{lll}
\hline \multicolumn{2}{l}{ Table 2} & Overview of the participant characteristics $(\mathrm{n}=18)$ \\
\hline Characteristic & Categories & Participants (n) \\
\hline Age & & $\mathrm{M}=45$ \\
& & $(\mathrm{SD}=15.0$, \\
& & range: $23-66)$ \\
Sex & Male & 4 \\
& Female & 14
\end{tabular}

$\begin{array}{lll}\text { Living situation } & \begin{array}{l}\text { Living alone } \\ \text { independently } \\ \text { Living with partner, } \\ \text { family or housemate }\end{array} & 6 \\ & \text { Assisted living } & 6 \\ \text { Work situation } & \text { Paid job } & 2 \\ & \text { Unpaid work } & 7 \\ \text { No work } & 9\end{array}$

\begin{tabular}{|c|c|c|}
\hline \multirow[t]{7}{*}{ Region } & Gelderland & 7 \\
\hline & Noord-Brabant & 3 \\
\hline & Noord-Holland & 2 \\
\hline & Drenthe & 2 \\
\hline & Vlaanderen (Belgium) & 2 \\
\hline & Overijssel & 1 \\
\hline & Zuid-Holland & 1 \\
\hline \multirow[t]{2}{*}{ Visual impairment } & Low vision & 6 \\
\hline & Blind & 12 \\
\hline \multirow[t]{12}{*}{ Traumatic events } & Sexual assault & 16 \\
\hline & Physical assault & 15 \\
\hline & $\begin{array}{l}\text { Emotional abuse/ } \\
\text { neglect by family }\end{array}$ & 8 \\
\hline & $\begin{array}{l}\text { Bullying/loneliness at } \\
\text { school }\end{array}$ & 3 \\
\hline & $\begin{array}{l}\text { Witnessing injury/harm } \\
\text { to others }\end{array}$ & 2 \\
\hline & Fire/struck by lightning & 2 \\
\hline & $\begin{array}{l}\text { Suicide of friend/close } \\
\text { one }\end{array}$ & 2 \\
\hline & $\begin{array}{l}\text { Aggression-related } \\
\text { incidents at work }\end{array}$ & 1 \\
\hline & $\begin{array}{l}\text { Acute vision loss due to } \\
\text { eye disease }\end{array}$ & 1 \\
\hline & $\begin{array}{l}\text { Incident during a } \\
\text { medical appointment }\end{array}$ & 1 \\
\hline & $\begin{array}{l}\text { Exposure to details of a } \\
\text { severe accident }\end{array}$ & 1 \\
\hline & Fall incident & 1 \\
\hline
\end{tabular}

\section{RESULTS}

\section{Participant characteristics}

The main characteristics of the 18 persons participating in this study are presented in table 2. The table shows that the majority of the participants were female $(n=14)$. They were from various age groups and had diverse living arrangements, and a majority did not have a paid job $(n=16)$. Most of the participants were from various regions in The Netherlands $(n=16)$ and had been recruited through the low-vision service centres $(n=10)$ as well as the patient association $(n=6)$. Two participants were from Flanders (Dutch-speaking part of Belgium) and had responded to the call in the newsletter from the patient association.

Two-thirds of participants were blind, while one-third had low vision. In almost all participants $(n=17)$, visual impairment was due to congenital or hereditary causes, of which the most common causes were retinitis pigmentosa, Leber hereditary optic neuropathy, retinopathy of prematurity and congenital cataract. One person had acquired blindness due to idiopathic panuveitis. Most participants had additional eye conditions such as glaucoma, nystagmus and retinal detachment.

Most participants identified multiple events as the cause of PTSD, including a combination of sexual, physical and emotional abuse over a prolonged period of time. Participants often discussed these types of trauma in an integrated way. Several participants additionally mentioned other types of traumatic events that contributed to the development of PTSD (table 2). Two participants mentioned a single traumatic event as the cause of PTSD, which included a kidnapping with sexual abuse and a fall in a hole.

Based on the analysis of the interview data, the results about the experiences of people with visual impairment with traumatic events, consequences of traumatic events and post-traumatic stress and PTSD-related care were dived into subthemes. For each of the subthemes, the role of visual impairment is described.

\section{Traumatic events}

Two topics were addressed with respect to the role of visual impairment in traumatic events: exposure to traumatic events and the experience of a traumatic event.

\section{Exposure to traumatic events}

The role of visual impairment in the exposure to traumatic events varied for different event types. According to some participants, the events they experienced would have happened regardless of their visual impairment. This included, for example, an event in which a participant was kidnapped, as the perpetrator was probably not aware of the visual impairment of the victim. Several other participants thought that the traumatic events would probably not have happened without the visual impairment. This included, for example, cases of abuse occurring at boarding schools for children with low vision or blindness, as participants explained that they otherwise would not have attended such schools. The fall accident could directly be contributed to the visual impairment as seeing the construction hole would have prevented it from happening. Also, witnessing the injury of a guide dog would not have occurred as a traumatic event: 
A guide dog that falls away, he was my everything, he was my life. He came into my life and he took me outside, he gave me something to live for. [...] and that accident, I think if I had not been blind, this would have never happened. (Woman aged 40-49 years, blind)

According to the majority of participants, their visual impairment had influenced the exposure to events only to some extent by increasing the likelihood that the event would occur. This mainly concerned events involving physical, sexual and emotional abuse. Participants explained that their impairment had contributed to low self-esteem and dependence on others and a lack of acceptance by family members or partners (on whom they depended) and peers. They thought this may have made them more vulnerable for experiences of abuse.

I think, the relation between me and my mom would have been much better if I hadn't had this impairment.[...] For years I was not allowed to walk with a cane because that would make my mother look bad. So I was dependent on them and I always had to hold someone's arm when walking and sometimes they would leave me standing next to the car and things like that. (Woman aged 20-29, blind)

You often can't keep up with others because of your visual impairment and you're often excluded. There was a boy who was sweet and kind, which made me really happy. I thought 'finally someone who sees me and who is not bothered by my impairment. [...] But well, the consequence [sexual abuse] was horrible. (Woman aged 50-59 years, low vision)

\section{Experience of a traumatic event}

The majority of participants indicated that the lack of visual information while an event occurred had influenced their experience of events. The visual impairment affected four aspects of events:

First, participants explained that they did not see the events coming, for example, in case of aggressive outbursts, punches or vehicle collisions. Because of this, it felt as if events occurred very suddenly and participants were being caught off guard.

Second, for some respondents, not knowing what was happening due to a lack of visual information contributed to feelings of insecurity and the stressfulness of the event.

Third, because participants had limited information about the situation, they often could not respond in a timely manner.

You don't see a punch coming so you are absolutely not resilient. My brother would enter my room and suddenly hit me. You know, had you seen it, you would have defended yourself or something, but that just wasn't possible. (Woman aged 20-29 years, blind)

Fourth, about half of the participants mentioned that their impairment hindered them from getting away from situations because it prevented them from identifying escape options. Some also indicated that a lack of self-reliance due to their poor sight prevented them from getting away, as they did not know where to go, how to get there and who to turn to.

At some points I thought about trying to get out of the van, but I just didn't see where I could open it and I think this stopped me from trying. And had I gotten out, how would I know where to go? I think that also stopped me. (Woman aged 30-39, low vision)

\section{Consequences of traumatic events}

Following the traumatic events, participants had experienced symptoms and matching formal DSM criteria for PTSD, including re-experiencing of the event, avoidance, negative thoughts and emotions, and hyperarousal. In addition to these symptoms, impaired functioning was evident for the stories of participants. Visual impairment seemed to impact consequences of trauma in diverse ways.

\section{PTSD symptoms}

Intrusions were affected by the lack of visual information during events. The senses that were used during the traumatic events largely determined the senses through which intrusions manifested themselves. Participants with residual sight reported intrusions of visual nature, while those people who were completely blind mostly experienced intrusions in terms of sound, feelings and smells. Although some of them explained that they also had some sort of mental image, they had no idea whether this matched reality.

With respect to avoidance of reminders of trauma, about half of the participants reported avoidance of certain social situations. Avoidance was also strongly related to feelings of distrust of others. Whereas some participants avoided social situations in general, others avoided specific situations such as contact with men, coworkers, peers or care providers. Several participants explained that since they were not able to see who exactly had been involved in the abuse or assault, they tried to stay away from peers and professionals related to boarding schools or institutions for people with visual impairment altogether.

For a long time I did not want contact with visually impaired people and organisations for people with impairments. Now sometimes you meet old classmates or others who went to the boarding school. Some are a little bit older and then you always think: were you involved in it or not? (Woman aged 40-49 years, blind)

Furthermore, some participants reported avoiding going out on the street, as they associated this with potential risks and danger. They were afraid of not being able to timely identify danger due to their impairment, which resulted in not going out of the house at all or sticking to familiar routes. This was most clear for the participant who 
had been kidnapped from the street and the participant who had fallen in a construction hole in the pavement.

Approximately half of the participants felt that the negative thoughts and emotions they experienced after trauma exposure were reinforced by their visual impairment. More specifically, their visual impairment seemed to strengthen negative feelings about themselves, others and the world in general. Their self-esteem and trust in others had already been low before trauma exposure and decreased further due to the impact of the traumatic event. In addition, the fact that participants could not identify facial expressions made them unsure about other people's intentions.

I just trusted no one, but I also could not see whether a person had good intentions or if I could walk somewhere safely and without any danger. (Woman aged 50-59 years, low vision)

The lack of visual cues about the environment also made them more aware of their own vulnerability and potential dangers in the world.

I think my blindness played a role, because I suddenly considered the world to be an unsafe place. I could not oversee things, literally. And I noticed everything I came across on the street, I saw every loose tile. (Man aged 60-69 years, blind)

Several participants discussed symptoms of hyperarousal in relation to their visual impairment. They explained having experienced a lot of tension and hypervigilance as they were constantly alert, which seemed enhanced by their fear that they would not be able to identify potential danger in time.

Although sleeping problems were prevalent, some participants indicated that this could (partly) be explained as a consequence of their visual impairment. Furthermore, several participants reported self-destructive behaviours in the form of automutilation and eating disorders.

Noticeable was that several participants explained that they experienced a very strong need for control. The lack of visual information made participants insecure about the safety of their environment and sometimes enhanced compulsive behaviour.

I would put out the trash and when I came back to my room I checked my entire room. So also under the cupboards, behind the cupboards, under the bed, behind the shower curtain, everywhere. I just wanted to be sure: they [parents] are not here. (Woman aged $40-49$ years, low vision)

\section{Functioning}

Almost all participants who had a job or study had to quit. For some of them, functioning was disrupted soon after the traumatic event(s) took place. Others were able to function for years, often in a mode of survival, before they broke down. The role of visual impairment was most clear in reinforcing the loss of social contacts and isolation.
People already experienced obstacles in mobility prior to the traumatic event due to their impairment, and they had been often dependent on others for participating in activities. Several participants explained that after the traumatic event, they experienced an increase in mobility problems and thus in dependency on others. At the same time, the threshold for engaging with others had become even higher, which caused many participants to withdraw from activities and social contact. As a result, participants often felt isolated and lonely.

I often can't follow the conversations if there are too many people at the table. I also don't see it if they look at me or if they are talking to me. This, on top of a lack of self-confidence, makes it hard to keep up with others. [...] Because of this I'm also quite lonely. (Woman aged $40-49$ years, low vision)

\section{PTSD-related care}

With respect to PTSD-related care, participants shared experiences in the help-seeking process and PTSDrelated treatment.

\section{Help-seeking process}

The process of seeking and getting help for PTSD varied widely among the participants. For some, especially those who experience single traumatic events, PTSD symptomatology was recognised early in the process, on which treatment was provided. For others, especially those suffering from complex trauma involving sexual, physical and emotional abuse, it took many years before help was sought and/or provided. Reasons for this were that symptoms sometimes appeared or intensified later on and that participants avoided care. In addition, PTSD symptoms were often not recognised or were attributed to other causes. Some participants described how their complaints were interpreted by others as being related to the visual impairment instead of to post-traumatic stress. In several cases, the need for PTSD treatment was recognised, but mental health professionals indicated not to be specialised in complex traumatisation or in visual impairment, which led to delays in provision of treatment.

\section{Treatment}

All participants had had some traditional form of psychotherapy, and they often received this several times in their lives. They often did not recall what kind of therapy exactly, but they described elements of cognitive-behavioural therapy. One participant specifically mentioned having had imaginary exposure therapy. In addition to the traditional types of psychotherapy, approximately two-thirds of the participants $(n=11)$ also had eye movement desensitisation and reprocessing (EMDR) using auditory stimuli via headphones $(n=9)$ and/or tactile stimuli via handheld buzzers $(n=4)$ or tapping on hands/knees $(n=4)$. Next to psychotherapy and EMDR, several participants mentioned other forms of treatment and care that they 
found helpful, including psychomotor therapy, yoga and mindfulness.

The role of the visual impairment in the treatment process was limited according to many participants. The aspects of treatment that required most adjustment or attention included treatment modality, communication and accessibility. Participants explained that some mental healthcare providers were not familiar with non-visual EMDR techniques. This was sometimes a reason not to start treatment, and other times professionals made an effort to get acquainted with suitable techniques.

They wanted to start EMDR, but that never happened.

[...] They didn't know how to do that with someone with a visual impairment and they did not know if I was stable enough or strong enough; a lot of this kind of excuses. (Woman aged 20-29 years, blind)

Despite the hesitation to apply non-visual EMDR among some professionals, all participants but one who followed EMDR experienced beneficial effects. They explained that EMDR helped to make the memories less traumatic 'taking the sharp edges off' and to reduce or eliminate the intrusions. This had been a very intensive process and several participants mentioned feeling unwell for several days after having had a session. Some of them needed additional assistance or support during those days. One participant explained that the EDMR had not worked for her, although she could not explain why.

Similar experiences were reported, for example, for certain group therapies and creative therapies.

With respect to communication, participants indicated that (mental) healthcare providers were regularly not used to communicating with people with a visual impairment. This meant that adaptations were needed by eliminating the use of visual tools during treatment, explaining more about what was going on and providing more verbal feedback.

You always have to communicate a lot. If you don't talk, you're also not communicating. Many people first have to learn to talk a lot to someone [...], to not point at something and say 'there it is'. You have to put me in a chair, hand everything to me and tell me where everything is. (Woman aged 40-49 years, blind)

Furthermore, participants explained that attention was needed for accessibility and suitability of facilities. Treatment facilities were not always easy for them to access, and it helped, for example, if they were assisted in reaching the location, if sessions always took place in the same room and if rooms were free of noise.

In addition, some participants thought that it helped when the role of their visual impairment in traumatic experiences and treatment processes was explicitly addressed. This could also help to unravel which symptoms could be attributed to either PTSD or the visual impairment, as they felt that sometimes symptoms were too easily attributed to a certain cause.

\section{DISCUSSION}

This study provides insight into experiences of people with visual impairment and PTSD. Although participants' stories are unique and diverse, the results clearly describe how visual impairment can play a role in various aspects related to trauma and PTSD.

Notably, combinations of various types of abuse, often occurring during childhood and/or adolescence, were common in our study population. The risk of experiencing abuse has been found to be higher in people with impairments compared with the general population. ${ }^{12-14}$ In our study, the vulnerability of this particular population was partly explained by attendance of boarding schools or institutions for people with visual impairment, which have been found to expose children to various types of abuse. ${ }^{15}$ Besides this, study participants described other instances of abuse in family context and abusive relations. In all cases of abuse, dependency, low self-esteem and/or a lack of acceptance by others played a role, and this was often (partly) attributed to having a visual impairment. Brunes and Heir, $\left({ }^{14}, \mathrm{p} 6\right)$ state that people with visual impairment may be more prone to sexual abuse as they are more likely to face social isolation and dependency and to have a lower socioeconomic status, and 'this makes it easier for a perpetrator to assert power and control over the victim'. Adverse childhood experiences and childhood abuse have been identified as risk factors for PTSD. ${ }^{16-18}$ In the light of the existing body of literature, the current study underlines the idea that abuse and disability are interlinked, and as such, visual impairment is hypothesised to be a risk factor in the development of PTSD.

Insights from our study suggest that visual impairment may contribute to the risk of PTSD by aggravating feelings of helplessness, insecurity and fear during and in the aftermath of traumatic events. This is in line with other studies about experiences with traumatic events among people with visual impairment, which showed that barriers in accessing the physical environment and information during and after events increased the levels of distress of participants. ${ }^{1920}$ Additionally, some studies described how the lack of crucial visual information during events negatively affected the ability to cope emotionally. ${ }^{26}$ Such peritraumatic emotional responses during or in the aftermath of the event were identified as important predictors of PTSD in a meta-analysis on PTSD predictors. ${ }^{21}$

PTSD symptoms and consequences in people with visual impairment described in the current study seem largely consistent with PTSD criteria as stated in DSM-5. Nonetheless, study participants often described how their visual impairment shaped the symptoms they experienced. This was most clear for intrusions, as visual content of intrusions may be limited for people who were poorsighted at the time of the event or lacking completely for people with congenital blindness. The dominant role of auditory intrusions in people with visual impairment has been previously described in two qualitative studies. ${ }^{22}$ With respect to other symptoms, visual impairment may have contributed to the severity of avoidance, negative 
thoughts and emotions and hypersensitivity, which is in line with other literature describing PTSD symptoms in people with visual impairment. ${ }^{126}$ A notable finding concerns the strong need for control found among several participants, which is not one of the common symptoms for PTSD. Possibly, these participants suffered from an undiagnosed comorbid obsessive compulsive disorder. However, it is also possible that the lack of visual information and the inability to visually identify possible threats triggered a stronger need for control, implying that these symptoms could also be considered in relation to PTSD.

Especially apparent in our results was the impact of trauma on the daily life of participants. The particular and severe impact of PTSD on social functioning of people with visual impairment has only scarcely been described in literature so far. Visual impairment in itself is associated with lower social functioning. ${ }^{23-25}$ Additionally, the current study shows that PTSD further reduces social functioning in terms of loss of work, studies and social contacts. Especially, social withdrawal and loneliness were often reported problems among the study participants.

Regarding the help-seeking process, there were some evident delays in treatment. As is the case for PTSD in general, participants' hesitation to seek care was often related to avoidance of trauma-related details and social withdrawal, likely strengthened by their visual impairment. A general lack of recognising PTSD among professionals and hesitance on their side with respect to the lack of knowledge regarding visual impairment further hampered this process. These findings suggest that the percentage of people with visual impairment receiving PTSD treatment may be even lower than the $53.5 \%$ found among the general population. ${ }^{7}$ This points at a need for better identification of PTSD in people with visual impairment. Such identification requires professionals providing low-vision services, mental healthcare and eye care to become more aware of the particular vulnerability of people with visual impairment with respect to trauma and to collaborate on this issue. Treatment may be possible both in a mental healthcare setting and in the context of low-vision services. Professionals in both settings may benefit from each other's expertise. Our study shows that even though mental health professionals may be hesitant to use EMDR in people with visual impairment as the preferred treatment modality (eg, eye movements) is not applicable, other modalities (using auditory or tactile stimuli) can be applied successfully.

One of the strengths in this study was the exploratory, qualitative design, which allowed for in-depth insights into this sensitive and largely unexplored topic. Characteristics of participants were heterogeneous with respect to age, visual impairment and living conditions, which contributed to the richness of data. Regarding some topics, new themes still emerged during the last interviews, indicating that saturation was not optimal yet. The study provides limited insight into experiences of persons with visual impairment and single trauma not involving abuse. Furthermore, recall bias may have influenced the data, considering the retrospective focus of the interviews. Lastly, inherent to the qualitative methodology, this study does not provide insights regarding the epidemiological profile of the target group or comparisons with the general population.

\section{CONCLUSIONS}

This study indicates that visual impairment seems to play a role in traumatic events and consequences of such events. The lack of visual information potentially contributes to the development of PTSD by shaping exposure to events, experiences of events and PTSD symptomatology. Insights from this study provide starting points for adapting pretraumatic and post-traumatic care to the needs of people with visual impairment. Recognition and treatment of PTSD in people with visual impairment can be improved to fit the needs of this vulnerable population and require collaboration between professionals from mental healthcare and low-vision services.

Acknowledgements We express our gratitude to the people with visual impairment and post-traumatic stress disorder who shared their experiences in interviews. We also appreciate the advice from the advisory committee of the study and the cooperation of the involved health professionals of the two low-vision service centres and The Eye Association Netherlands in disseminating information about our study.

Contributors The executive researchers (LH and HA), project advisor (PV), project leader (GR) and principal investigator (RN) conceived the study and its design. LH, $\mathrm{HA}$ and RN adapted and developed the interview scheme. Data collection, analysis and interpretation were performed by $\mathrm{LH}$, in collaboration with HA and RN. LH drafted the manuscript, which was revised by the other authors (HA, PV, GR and RN). All authors read and approved the final manuscript.

Funding This work was supported by ZonMw (The Netherlands Organisation for Health Research and Development, grant number 60-63900-98-007). The funders had no role in study design, data collection and analysis, decision to publish, or preparation of the manuscript.

Competing interests None declared.

Patient consent for publication Not required.

Ethics approval The study protocol was approved by the Medical Ethics Review Committee of the VU University Medical Center. All procedures performed in this study were in accordance with the ethical standards of the Amsterdam Public Health research institute and with the 1964 Helsinki Declaration and its later amendments or comparable ethical standards.

Provenance and peer review Not commissioned; externally peer reviewed.

Data availability statement Data are available upon reasonable request. The data that support the findings of this study are available on reasonable request from the corresponding author. The data are not publicly available due to their containing information that could compromise the privacy of research participants. Interview guidelines are included as supplementary material.

Supplemental material This content has been supplied by the author(s). It has not been vetted by BMJ Publishing Group Limited (BMJ) and may not have been peer-reviewed. Any opinions or recommendations discussed are solely those of the author(s) and are not endorsed by BMJ. BMJ disclaims all liability and responsibility arising from any reliance placed on the content. Where the content includes any translated material, BMJ does not warrant the accuracy and reliability of the translations (including but not limited to local regulations, clinical guidelines, terminology, drug names and drug dosages), and is not responsible for any error and/or omissions arising from translation and adaptation or otherwise.

Open access This is an open access article distributed in accordance with the Creative Commons Attribution Non Commercial (CC BY-NC 4.0) license, which permits others to distribute, remix, adapt, build upon this work non-commercially, and license their derivative works on different terms, provided the original work is 
properly cited, appropriate credit is given, any changes made indicated, and the use is non-commercial. See: http://creativecommons.org/licenses/by-nc/4.0/.

ORCID iD

Alida J van der Ham http://orcid.org/0000-0001-5586-1631

\section{REFERENCES}

1 Brunes A, Hansen MB, Heir T. Post-Traumatic stress reactions among individuals with visual impairments: a systematic review. Disabil Rehabil 2019;41:2111-8.

2 Saur R, Hansen MB, Jansen A, et al. Visually impaired individuals, safety perceptions and traumatic events: a qualitative study of hazards, reactions and coping. Disabil Rehabil 2017;39:691-6.

3 Bisson Jl, Cosgrove S, Lewis C, et al. Post-Traumatic stress disorder. BMJ 2015;351:h6161.

4 American Psychiatric Association. Diagnostic and statistical manual of mental disorders (DSM-5尺). Arlington, VA: American Psychiatric Pub, 2013.

5 Heir T, Hansen M, Brunes A. Visual Impairments. In: Assisting people with disabilities in case of disaster. Bonn, Germany: Federal Office of Civil Protection and Disaster Assistance, 2017: 83-95.

6 Van der Ham AJ, van der $\mathrm{Aa} \mathrm{H}$, Brunes A. The development of posttraumatic stress disorder in individuals with visual impairment: a systematic search and review. Ophthalmic Physiol Opt.

7 Koenen KC, Ratanatharathorn A, Ng L, et al. Posttraumatic stress disorder in the world mental health surveys. Psychol Med 2017:47:2260-74.

8 Brunes A, Heir T. Major depression in individuals with visual impairment, associations with characteristics of vision loss, and relation to life satisfaction, 2019. Available: https://ssrn.com/ abstract $=3323116$

9 World Health Organization. International classification of diseases 11th revision: 2019, 2019. Available: https://icd.who.int/browse10/ 2019/en/

10 Green J, Thorogood N. Qualitative methods for health research. London, UK: Sage, 2018.

11 Barnes M, Cotterell P. Critical perspectives on user involvement. Birstol, UK: Policy Press, 2012.

12 Plummer SB, Findley PA. Women with disabilities' experience with physical and sexual abuse: Review of the literature and implications for the field. Trauma Violence Abus 2012;13:15-29.
13 Byrne G. Prevalence and psychological sequelae of sexual abuse among individuals with an intellectual disability: a review of the recent literature. J Intellect Disabil 2018;22:294-310.

14 Brunes A, Heir T. Sexual assaults in individuals with visual impairment: a cross-sectional study of a Norwegian sample. BMJ Open 2018;8:e021602.

15 Commissie Onderzoek naar Geweld in de Jeugdzorg. Onvoldoende beschermd - Geweld in de Nederlandse jeugdzorg van 1945 tot heden. Den Haag, The Netherlands Commissie Onderzoek naar Geweld in de Jeugdzorg; 2019.

16 Ammerman RT, Lubetsky MJ, Stubenbort KF. Maltreatment of children with disabilities. In: Case studies in family violence. Boston, MA: Springer, 2000: 231-58.

17 Howe D. Disabled children, maltreatment and attachment. Br J Soc Work 2006;36:743-60.

18 Brewin CR, Andrews B, Valentine JD. Meta-Analysis of risk factors for posttraumatic stress disorder in trauma-exposed adults. $J$ Consult Clin Psychol 2000;68:748-66.

19 Shpigelman C-N, Gelkopf M. The experiences and needs of individuals with disabilities exposed to chronic political violence. Disabil Rehabil 2017;39:23-35.

20 Good GA, Phibbs S, Williamson K. Disoriented and immobile: the experiences of people with visual impairments during and after the Christchurch, New Zealand, 2010 and 2011 earthquakes. J Vis Impair Blind 2016;110:425-35.

21 Ozer EJ, Best SR, Lipsey TL, et al. Predictors of posttraumatic stress disorder and symptoms in adults: a meta-analysis. Psychol Bull 2003;129:52-73

22 Au-Yong A, Firth W. Post-Traumatic stress disorder. PTSD in a blind patient - a case report, 2006. Available: http://www.priory.com/ psych/ptsdblind.htm

23 Verstraten PFJ, Brinkmann W, Stevens NL. Loneliness, adaptation to vision impairment, social support and depression among visually impaired elderly. Proceedings of the International Congress; 4-7 2005, London, UK, 2005:317-21.

24 Nyman SR, Dibb B, Victor CR, et al. Emotional well-being and adjustment to vision loss in later life: a meta-synthesis of qualitative studies. Disabil Rehabil 2012;34:971-81.

25 Brunes A, B Hansen M, Heir T. Loneliness among adults with visual impairment: prevalence, associated factors, and relationship to life satisfaction. Health Qual Life Outcomes 2019;17:24. 